\title{
Diagnosis of human-induced degradation of soils of the Azov-Cuban lowland
}

\author{
V.P. Vlasenko*, A.V. Osipov, and V.N. Slyusarev \\ Kuban State Agrarian University (Kuban SAU), Krasnodar, Russia
}

\begin{abstract}
The work presents the observational data of soil cover structure dynamics, changes in soil composition and properties under the influence of anthropogenic impact. A decrease of $6.0-7.4 \%$ in the share of black soils (Chernozem) over 50 years of observations and a corresponding increase in the area of waterlogged soils associated with closed depressions have been revealed. Due to the high dynamism of soil density with changes in its moisture content, a criterion has been sought to characterize this dependence and a method has been proposed to describe it using dynamic curves. The amplitude of density fluctuations and its dependence on the severity of anthropogenic degradation - $59-78 \%$ - has been established. Correlation analysis confirmed a medium strength relationship (determination coefficient $0.39-0.42$ ) between shrinkage and specific surface area of initial degradation soils and a strong relationship (determination coefficient $0.79-0.86$ ) in meadow-chernozem compacted soils. A strong correlation has been found between the volumetric shrinkage and fines content in the size distribution (determination coefficient 0.84-0.96). A new diagnostic criterion ("T" criterion) for the intensity of hydrometamorphism and, in general, for the physical aspect of anthropogenic soil degradation has been proposed.
\end{abstract}

\section{Introduction}

The concept of anthropogenic degradation combines degradation processes caused by technogenesis. There are quite a number of definitions of soil degradation in general and soils in particular - "...soil degradation is understood as the processes and results of changes in their properties and natural regimes, collectively leading to changes in soil functions as an element of the ecological system and reduction of soil fertility" [1-5].

The novelty of the approach proposed in the research is ensured by the comprehensiveness of the issue in hand:

- on the one hand, the in-depth analysis of the dynamics of soil properties degraded due to anthropogenic impact will provide information on the real level of soil fertility, which is the basis for the development of new (promising) farming systems;

- on the hand, the concepts of transition of the agrarian economy to adaptive landscape specific farming system, private methods, particular economic and mathematical models, refined in accordance with the features of the modern market economy, will be a working

\footnotetext{
* Corresponding author: kirsanovi@mail.ru
} 
tool to assess the productive potential of natural landscapes, environmental and economic evaluation of agricultural systems, and justification of priorities for innovation development of the industry.

The purpose of this research is to identify the dynamics of soil cover structure, composition and properties of soils due to anthropogenic degradation

The objectives are as follows:

- analysis of the land topsoil structure of agriculturally used areas and identification of the main directions of its transformation;

- search for new approaches to the diagnosis of degradation processes;

The relevance of the research is due, on the one hand, to the scale and rate of negative processes (erosion, waterlogging) of up to 1.8 million hectares of land in the Krasnodar region alone; on the other hand, to the lack of current information on the composition and properties of soils; from yet another perspective, to the currently existing imbalance between the recognition of concepts "land, land plot" as a priority over "soil", and the totally unjustified overemphasis on agrochemical characteristics of soils. The physical basis of landscape (agrarian landscape) stability, consisting in soil inalterability, primarily the solid soil phase, which is the material (physical) basis of agrarian landscape stability, remains poorly understood, while the anthropogenic impact on soils is increasing.

The research is aimed at studying the dynamics of soil structure, composition and properties of soils (chernozems) of the Azov-Kuban lowland. Problems related to classification, nomenclature and diagnosis of soils transformed due to hydrometamorphism, erosion, justification of terms and formulation of concepts (waterlogging, degradation, physical degradation, slitogenesis (development of vertic properties in soils), permissible erosion rate, etc.) have been covered in works of a large number of authors $[6,7,8,9]$. Views on the soil-forming processes in soils hydrometamorphised soils (without the naming of the latter as such) is presented in works by N.B. Khitrova [10, 11]. There is also a fairly wide range of views on the diagnostic criteria for the degradation in soils, and justification for the application of one or another criterion is given [12-14].

The study of research materials on the topic of interest has suggested that humaninduced degradation of soils is determined not only and not so much by anthropogenic impact, but by the properties of the soil itself, especially its solid phase. The nature of the dependence of its physical state indicators (density, shrinkage) on humidity varies and can serve as an indicator of the presence or absence of signs of degradation. It is necessary to find indicators characterizing the dynamics of the process of changing the physical state of the soil under anthropogenic impact.

\section{Objects and methods}

The objects of the research were the soils of the Azov-Kuban plain (Timashevsk district, Krasnodar), subject to anthropogenic degradation processes: alkaline chernozems and meadow-chernozemic compacted soils (Classification ... 1977) or clay-illuvial chernozems and clayed hydrometamorphic (quasigley) and vertic chernozems (as per Russian soil classification, 2004) [15].

The analysis of soil cover structure dynamics was based on materials of soil researches of the land areas of Yeisky, Timashevsky and Dinsky districts and city of Krasnodar (19722020), carried out by Kubangiprozem institute and personally by the authors.

The dynamics of soil density with changes in moisture content (drying) was studied in soil samples taken by the ample ring method with a volume of $50 \mathrm{~cm} 3$. The soil moisture at the time of sampling is close to the lowest moisture capacity (MC), the replication is three and five times, depending on the horizon. Subsequent drying for 18 days was accompanied by daily weighing and measurement of geometric parameters with a 3D scanner. 
The specific surface area of the solid phase was determined using the standard method, a new method was the use of evacuation, which accelerated the saturation process [16].

Volumetric shrinkage was investigated in samples taken for the soil density dynamics analysis using the same pattern. The shrinkage was calculated using the standard method, with moisture parameters of $28-31 \%$ at beginning of the experiment and $6-10 \%$ (by weight) at the end.

\section{Results and discussion}

\subsection{Changes in the structure of soil cover (SSC) and area of waterlogged lands (WLA)}

were identified by analyzing and overlaying the soil maps of the previous rounds of the survey carried out by the Kubangiprozem institute. Our own research suggests that the development of physical soil degradation, especially on arable land, is caused by an increase in the intensity of anthropogenic impact against the background of changing (often cyclical) climatic indicators. This trend is confirmed by the increase in the area of wetlands over the last half century. For example, the percentage of waterlogged lands in Dinskiy and Timashevskiy districts has doubled (from 9.0-15.2 to 18.7-29.7\%), and in Krasnodar city it has tripled (from 7.9 to $25.7 \%$ ).

In our opinion, the increase in WLA is less related to an increase in precipitation, but is mainly due to a change in the structure of soil cover (SSC) of lowland and basin agrarian landscapes towards an increase in the proportion of semihydromorphic chernozem analogues.

For example, in Timashevsk district there has been a $3.5-4.8 \%$ decrease in the share of typical chernozems, a complete disappearance of leached chernozems and a $7.2 \%$ increase in the share of meadow-chernozemic compacted soils by $6.0 \%$ and meadow-chernozemic vertic soils by $7.4 \%$ over half a century.

\subsection{Diagnosis of anthropogenic degradation}

The list of soil properties, and especially parameters that could provide a basis for concluding the presence or absence of anthropogenic degradation is quite large, which is due both to the diversity of its manifestation and to the differences in the approaches applied by the researchers [17]. We will limit to indicators characterizing physical degradation, which is often a consequence of anthropogenic impact, leading to development and being itself the result of hydrometamorphism of soils. Since the essence of hydrometamorphism consists of slitogenesis (almost always) and often, but not always, of gleyification, it is logical to use morphological manifestations, indicators of physical state of soils caused by these processes as diagnostic attributes.

N.B. Khitrov [18], F.I. Kozlowsky [19] et al. The leading diagnostic sign of slitogenesis is morphologically assigned to slickensides. While generally agreeing with this approach, the difficulty of applying this indicator at high (wet) and low (dry) humidity levels must, however, be noted. The use of soil density as a diagnostic criterion also requires the specification of moisture conditions, which is very impractical. There are many suggestions in the literature for the use of indicators characterizing slitogenesis as a process of compaction, swelling and shrinkage.

Despite the diversity of approaches, specific surface area, shrinkage and swelling, and particle convergence are the most common [20]. In our study we used the following system of indicators - fractional makeup (silt and physical clay content), specific surface area of 
the solid phase, soil density (dynamics in the range 30-5\% of moisture weight percentage). The results were subjected to correlation analysis, in order to identify correlations between each other and in relation to the severity of anthropogenic degradation (hydrometamorphism).

\subsection{Density of soils}

During the observation of soil samples changing in the process of drying it was found that the maximum density at $5 \%$ moisture content was $1.7-2.0 \mathrm{~g} / \mathrm{cm}^{3}$ for samples of meadowchernozemic vertic soils. Density of meadow-chernozemic compacted soils does not exceed $1.5-1.7 \mathrm{~g} / \mathrm{cm}^{3}$. The amplitude of the change in density relative to the original density also varied, ranging from $64 \%$ in compacted soils to $75 \%$ in vertic soils.

Form of curves (Fig. 1) and, especially, their location in relation to the coordinate axes are individual and are determined primarily (but not exclusively) by a set of physical properties of the soil. The analysis of the curves characterizing the investigated dependence for the arable layer of the studied soils showed a pattern not noted by previous researchers: the slope of the curves to the X-axis increases depending on the severity of hydrometamorphism. In the deeper layers, this process is reflected in an increase in curvature, from a straight line in meadow-chernozemic compacted soils to curves of maximum steepness in meadow-chernozemic vertic soils.

An important process parameter is the slope of the curve of the relationship under study, the physical meaning of which is to characterize the speed of the process.

There is a very significant differentiation in this indicator for soils of different degrees of hydrometamorphism in particular and anthropogenic degradation in general $-55 \%$. While we have established a high degree of correlation between the curve slope angle and the specific surface area of the solid phase of soils, first of all for soils with pronounced signs of hydromorphism, there is a reason to propose this criterion (" $\mathrm{T}$ " criterion - in mathematical sense, the tangent of the slope angle to the axis of abscissas) as an indicator of hydrometamorphism and of physical degradation of soils in general. We intend to investigate the possibility of using it as an indicator of the degree of hydrometamorphism.

\subsection{The specific surface area and soil shrinkage}

The specific surface area (SSA) is considered by many researchers to be the reasonably integral index reflecting the geometry of the solid soil phases. Our research has found a rather significant difference in the specific surface area of soils with different degrees of hydrometamorphism.

The variability of specific surface area is associated with different degree of dispersion of solid phase caused by intensity and duration of hydrometamorphism and, consequently, the index of SSA can serve as a diagnostic criterion of anthropogenic degradation of waterlogged soils in lowland and basin agrarian landscapes. 
a)

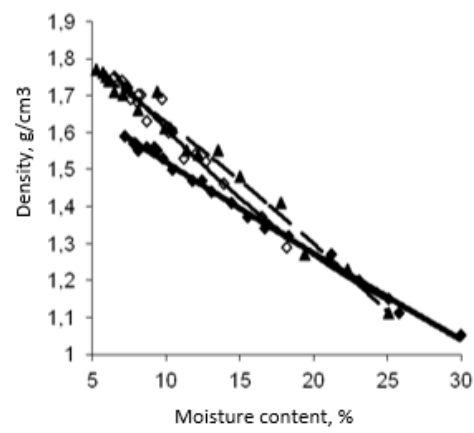

b)

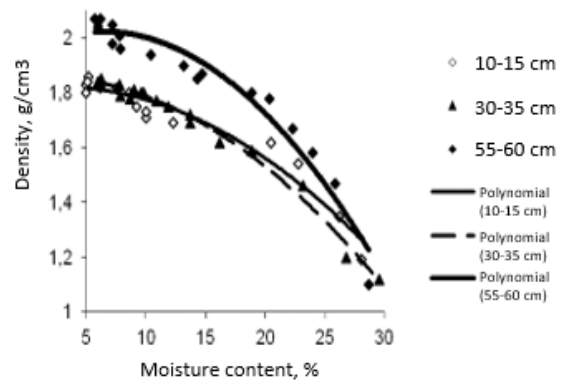

Fig. 1. Dynamics of soil density on drying: a) meadow-chernozemic compacted soils, b) meadowchernozemic vertic soils.

Shrinkage was determined in the same soil samples in which soil density dynamics was analyzed, which to a certain extent avoided the influence of soil mass heterogeneity, both in the vertical and horizontal directions. The method we used to study shrinkage was no different from conventional methods. The only assumption we made was that the shape (regularity) of the cylindrical specimen remained unchanged during drying.

Based on the data obtained, plots of soil shrinkage (b shr) and moisture content (W) have been prepared (Fig. 2).

a)

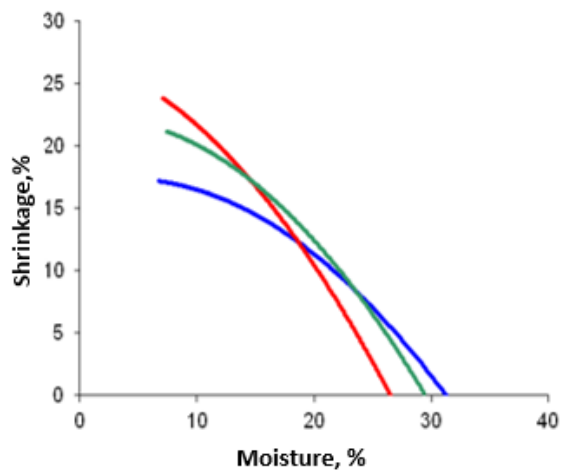

b)

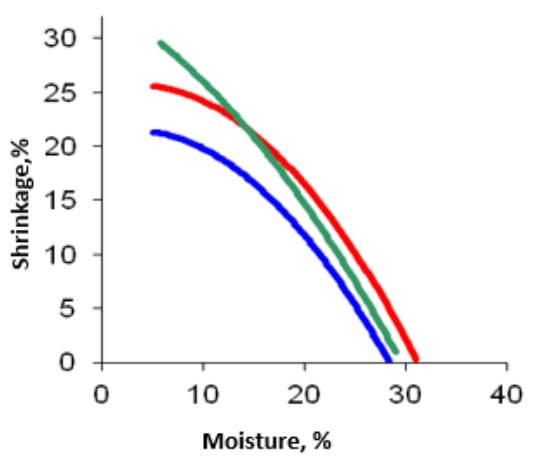

Fig. 2. Progress of soil shrinkage during drying, meadow-chernozemic compacted soils (a), meadowchernozemic vertic soils (b)

Legend:sample depth

$-10-15 \mathrm{~cm}$

$-30-35 \mathrm{~cm}$

$-55-60 \mathrm{~cm}$

According to the views of Joang and Varkentin [14], which we share, four shrinkage stages are distinguished: structural (I), normal (II), residual (III), shrinkage-free (IV), whose criterion is the different ratio of soil volume to evaporated water.

In our research, stage I shrinkage was absent in all samples, probably due to their high initial humidity (28-30\%). In leached chernozems, the shrinkage course corresponds to stage II, when the change in soil volume is due to a decrease in water volume due to evaporation. The shrinkage rate of leached chernozem horizons does not vary and is described by a range of $16-25 \%$. 
In hydrometamorphised soils, the shrinkage process is different: initially the process corresponds to the normal (II) and residual (III) stages. The humidity at which this transition takes place varies:

- higher (19\%) in vertic soils;

- significantly lower (14\%) in the compacted soils.

The transition to stage IV takes place at $12-14 \%$ moisture content, varying slightly by horizon. Probably at this stage, occurring quite quickly, there is a strong compaction of the soil and the formation of cracks.

This is due to an increase in the moisture gradient between the surface of the units and their interior, not compensated for by transfer of moisture from the interior of the units to the surface. Stretching forces during shrinkage cause cracks to form. At this stage, the change in moisture content does not exceed 5\%, and its (effort) magnitude correlates with the degree of hydrometamorphism. The latter circumstance is associated with more pronounced fissuring in vertic soils than in compacted soils.

In terms of volume shrinkage, the investigated soils differ significantly both in the arable layer and in the profile, ranging from $19 \%$ to $30 \%$. The maximum value was observed in meadow-chernozemic vertic soils at a depth of $55-60 \mathrm{~cm}$.

In the upper part of the profile there is a medium correlation dependence of volumetric shrinkage on specific surface in meadow-chernozemic compacted soils $-r^{2}=0.46-0.49$ and strong in meadow-chernozemic vertic soils $-r^{2}=0.77-0.81$.

The marked decrease in the correlation coefficient in the meadow-chernozemic vertic soils horizon $\left(\mathrm{r}^{2}=0.77\right)$ is probably due to a more complex correlation relationship and requires further investigation into the selection of a more adequate model.

A strong correlation between the volume shrinkage and silt fraction content for all horizons of the soils studied is indicated by a determination coefficient of 0.81-0.94.

\section{Conclusions}

1. As a result of the research, the direction of SSC dynamics of the Azov-Kuban lowland in the development of hydrometamorphism caused by anthropogenic degradation has been revealed, consisting in an increase in the proportion of semihydromorphic analogues of black soils by $6.0-7.4 \%$ over a half-century period of observation.

2. A difference has been found in the amplitude of the density change of soil samples when drying, towards an increase of $11 \%$ between soils with different degrees of hydromorphism and compaction.

3. Statistical analysis has allowed to establish a link between the average power of shrinkage of soils and their specific surface area (determination coefficient $=0.44-0.49$ ) in meadow-chernozemic compacted and strong (determination coefficient $=0.77-0.81$ ) in meadow-chernozem vertic soils. A strong relationship has been found between the volumetric shrinkage and silt content in all soil horizons studied (determination coefficient $=0.81-0.94$ )

4. The possibility of using the indicator "slope of the curve of dependence characterizing the dynamics of soil density during the changes in its moisture content in relation to coordinate axes" (criterion T) has been studied. The high correlation ratio of this index with specific surface of a firm phase of soils at meadow- and meadow-chernozemic compacted and vertic soils of $0.70-0.91$ at a level of probability 0.95 allows its use as an indicator of the presence of hydrometamorphism and, in general, of anthropogenic soil degradation in its physical aspect to be considered appropriate. 


\section{Acknowledgment}

The work was performed with the financial support of the Russian Foundation for Basic Research grant 19-44-230008 and the administration of Krasnodar region.

\section{References}

1. A. V. Gordeev, G. A. Romanenko, Problems of agricultural land degradation and productivity recovery in Russia, 68, 10 (2008)

2. I. Coxhead, R. Øygard, Land Degradation, 146 (Cambridge University Press, 2007)

3. P. F. Loiko et al, Modern agricultural land use in Russia: state, problems and prospects, 229 (M.: Publishing house RAGS, 2007)

4. I. O. Alyabina, V. A Androkhanov, V. V. Vershinin, S. N. Volkov, N. F. Ganzhara, G. V. Dobrovolsky, A. V. Ivanov, A. L. Ivanov, E. A. Ivanova, L. I. Ilyin et al, Unified State Register Of Soil Resources Of Russia. Version 1 (2014)

5. A. L. Ivanov, State, rational use and protection of land, 6-1(139), 22 (2015)

6. O. S. Bezuglova, O. G. Nazarenko, I. N. Iljinskaya, Arid Ecosystems, 10(2), 93 (2020)

7. N. M. Novikova, O. G. Nazarenko, N. A. Volkova, Ecosystems: ecology and dynamics, 1(2), 21 (2017)

8. O. S. Bezuglova, K. S. Kazeev, S. I. Kolesnikov, O. G. Nazarenko, In the collection: The current state of chernozems. Proceedings of the international scientific conference, 6 (2013)

9. F. R. Zaidelman, A. S. Nikiforova, L. V. Stepantsova, T. V. Krasina, V. N. Krasin, Eurasian Soil Science, 47(4), 223 (2014)

10. Yu. N. Vodyanitsky, Diagnostics of waterlogged mineral soil, 95 (2008)

11. V. P. Vlasenko, Scientific works, 179 (2012)

12. N. B. Khitrov, L. V. Rogovneva, E. P. Zazovskaya, Eurasian Soil Science, 51(7), 731 (2018)

13. U. Simsek, F. Mikailsoy, E. Erdel, E.V. Shein, A.G. Bolotov, Eurasian Soil Science, 52(3), 296 (2019)

14. V.F. Utkaeva, E.B. Skvortsova, V.N. Shchepot'ev, P.M. Sapozhnikov, Eurasian Soil Science, 42(2), 151 (2009)

15. M. I. Gerasimova, N.B. Khitrov, I. I. Lebedeva, Journal of Soil Science Institute named after V. V. Dokuchaev, 102, 5 (2020)

16. E.V. Shein, Eurasian Soil Science, 48(7), 712 (2015)

17. E. V. Shein, T. Sakunkonchak, Y. Y. Milanovskii, D. D. Khaidapova, V. I. Lazarev, Y. Y. Aidiev, Y. Y. Kuznetsov, Eurasian Soil Science, 44(10), 1097 (2011)

18. N. B. Khitrov, Eurasian Soil Science, 45(9), 834 (2012)

19. A. S. Sorokin, G. S. Kust, Eurasian Soil Science, 48(1), 63 (2015)

20. E. V. Shein, Eurasian Soil Science, 48(7), 712 (2015) 